\title{
Stability of Nonlocal Stochastic Volterra Equations
}

\author{
Sheila A. Bishop ${ }^{1 *}$, Agatha C. Nnubia ${ }^{2}$
}

1. Department of Mathematics, University of Lagos, Nigeria

2. Department of Mathematics, Nnamdi Azikiwe University, Awka, Nigeria

*Corresponding author: asbishop@unilag.edu.ng

\section{Article Info}

Received: 12 December 2020 Revised: 01 June 2021

Accepted: 11 June 2021
Available online: 17 November 2021

\begin{abstract}
In this paper, we study Ulam-Hyers-Rassias stability of solutions for nonlocal stochastic Volterra equations. Sufficient conditions for the existence and stability of solutions are derived using the Gronwall lemma. The advantage of our model equation is that it allows for additional measurements leading to better results compared to models with local initial conditions. Examples are solved to illustrate the applications of the results.
\end{abstract}

Keywords: Ulam-Hyers-Rassias stability, Stochastic Volterra equation, Gronwall lemma, Nonlocal conditions.

MSC2010: 37L05, 47J35, 47H10, 93D20

\section{Introduction}

The study of Volterra differential and integral equations with classical initial conditions have been of interest due to their several applications in various fields of science such as semiconductors, population dynamics, heat conduction, fluid flow, etc., see [1,2,7,9-20,23]. Differential equations with nonlocal and functional conditions have become an active area of research. The study of nonlocal problems is driven not only by theoretical interest but also because they occur naturally when modelling real-world applications. For example several phenomena in engineering, physics and life sciences can be described by employing differential equations subject to nonlocal initial conditions. See $[3-6,9,13,15,17,20-23]$. However, there are not much literature on the theory of stochastic Volterra equations with nonlocal conditions (see [17, 19,23] and the references therein). Some properties of the solutions to differential equations of Volterra type were studied by $[2,8,9$, $11,12,14,16,17,23] .[7,8,10-12]$ analised some types of stability (Ulam, Hyers-Ulam, and HyersUlam-Rassias) for nonlinear integro-differential Volterra equations and Volterra integral equations by using fixed-point arguments and the Bielecki metric techniques. [14] extended the work of [8] to a class of nonlinear stochastic integral equation of Volterra type. Of interest here is the work of [14], where existence and stability of the solution of stochastic Volterra integral equation is guaranteed if the following conditions are satisfied: given a group $G_{1}$, a metric group $\left(G_{2}, d\right)$, and $\epsilon>0$, there exists a $\delta>0$ such that the map $f: G_{1} \rightarrow G_{2}$ satisfies $\rho(f(x y), f(x) f(y))>\delta \forall x, y \in G_{1}$, then a homomorphism $T: G_{1} \rightarrow G_{2}$ exists and is stable provided a solution exists for such a problem. Ulam-Hyers-Rassias (U-H-R) stability of a nonlocal stochastic Volterra integral equation (NSVIE) 
is studied. We use Gronwall's lemma and some other analytical tools to establish the results. Our results extend and improve corresponding theorems in the existing literature concerning stochastic Volterra equations. In the sequel, we give some background definitions and some technical results in section 2, while section 3 is devoted to proving the main theorem and in section 4 , we present some examples.

\section{Preliminaries}

We introduce and study the stability of the following nonlocal stochastic Volterra equation

$$
\begin{aligned}
d y_{t} & =F\left(t, y_{t}\right) d t+G\left(t, y_{t}\right) d W_{t} \\
y(0) & =y_{0}+g(y), t \in[0, T] .
\end{aligned}
$$

$F(t, y)$ and $G(t, y)$ are $\Sigma_{t}$-measurable functions. $g(y()$.$) is the nonlocal condition. W_{t}$ is a Brownian motion defined on a given probability space. $y_{0}$ is an $\Sigma_{0}$-measurable random variable independent of $W_{t}$, and $y_{t} \in C$.

Let $(\Omega, \Sigma, \mathbf{P})$ be a complete probability space equipped with a filtration $\left\{\Sigma_{t}\right\}_{0 \leq t \leq T}$ and let $\|\cdot\|_{p}=$ $\left(E|.|^{p}\right)^{\frac{1}{p}}$ be the norm of the space $L^{p}(\Omega, \mathbf{P}), p>0$.

Let $C:=C\left(I, L_{a d}^{p}(\Omega, \Sigma, \mathbf{P})\right): I \rightarrow L_{a d}^{p}(\Omega, \Sigma, \mathbf{P})$ denote the space of all continuous stochastic processes $x(t, \omega)$ such that each $x(t, \omega)$ is adapted to the filtration $\left\{\Sigma_{t}\right\}$ and $E\left(\int_{0}^{t}|x(s)|^{p} d s\right)<\infty$, $I:=[0, T]$.

Equation (2.1) is better understood in integral form as

$$
y_{t}=y_{0}+g(y(.))+\int_{0}^{t} F\left(s, y_{s}\right) d s+\int_{0}^{t} G\left(s, y_{s}\right) d W_{s}, t \in I
$$

Definition 2.1. Let $v>0$. The problem (2.2) is said to be Ulam-Hyers-Rassias (U-H-R) stable with respect to $\epsilon>0$ if for every solution $y_{t} \in C$ of the inequality

$$
\left\|y_{t}-\left[y_{0}+g(y(.))\right]-\int_{0}^{t} F\left(s, y_{s}\right) d s+\int_{0}^{t} G\left(s, y_{s}\right) d W_{s}\right\|_{p} \leq \epsilon
$$

we can find another solution $z_{t} \in C$ of $(2.2)$ such that

$$
\left\|y_{t}-z_{t}\right\|_{p} \leq v \epsilon, t \in I
$$

Definition 2.2. The problem (2.2) is said to be Ulam-Hyers-Rassias (U-H-R) stable with respect to $\varphi(t)$ if we can find a constant $M_{\varphi}>0$ such that for every solution $y_{t} \in C$ of the inequality

$$
\left\|y_{t}-\left[y_{0}+g(y(.))\right]-\int_{0}^{t} F\left(s, y_{s}\right) d s+\int_{0}^{t} G\left(s, y_{s}\right) d W_{s}\right\|_{p} \leq \varphi(t),
$$

there exists another solution $z_{t} \in C$ of (2.2) such that

$$
\left\|y_{t}-z_{t}\right\|_{p} \leq M_{\varphi} \varphi(t)
$$

Lemma 2.1 (Gronwall Lemma) Let $\varphi(t), \psi(t) \in C\left([0, T]_{+}\right)$, where $\varphi(t)$ is nondecreasing. If $u(t) \in C\left([0, T]_{,+}\right)$is a solution of the following inequality

$$
u(t) \leq \varphi+\int_{0}^{t} \psi(s) u(s) d s, s, t \in[0, T]
$$

then

$$
u(t) \leq \varphi \exp \left(\int_{0}^{t} \psi(s) d s\right), s, t \in[0, T]
$$


The following result guarantees the existence of a unique continuous solution of problem (2.2).

Theorem 2.2. Assume that $F(t, y), G(t, y)$ and $g(y)$ are real valued-measurable functions on $C$ and $F(t, y), G(t, y)$ satisfy the Lipschitz and linear growth conditions in $y$. Suppose that also, the nonlocal initial condition $y_{0}+g(y)$ is such that $\left\|y_{0}+g(y)\right\|^{p}<\infty$. Then the nonlocal problem (2.2) has a unique continuous solution $y_{t}$ on $[0, T]$.

Proof: The proof is simply an adaptation of the proof of Theorem 1 in [14], to this present setting. Theorem 2.3. ([14]) Let $p \geq 2$ and let $f \in C$ be such that

$$
E\left[\int_{a}^{b}|f(t)|^{2} d t\right]<\infty
$$

then

$$
E\left|\int_{a}^{b} f(t) d W_{t}\right|^{p} \leq \gamma_{1} \cdot E\left[\int_{a}^{b}|f(t)|^{p} d t\right],
$$

where $\gamma_{1}=\left(\frac{p(p-1)}{2}\right)^{\frac{p}{2}}(b-a)^{\frac{p-2}{2}}$.

We state the following assumptions for $y, z \in C$ and $a, b \in I$.

$\left(H_{1}\right) F(t, y)$ and $G(t, y)$ are measurable functions taking values in $I \times C$.

Let $K>0, L>0$, and $L_{g}>0$ be positive constants such that

$\left(H_{2}\right)|F(t, y)-F(t, z)| \leq K|y-z|,|G(t, y)-G(t, z)| \leq K|y-z|$;

$\left(H_{3}\right) F(t, y) \leq L(1+|y|), G(t, y) \leq L(1+|y|)$;

$\left(H_{4}\right)|g(y())-.g(z()).| \leq L_{g}|y-z|, \zeta:=\max _{y \in C} \| g(y() \| ;$.

$\left(H_{5}\right)\left(1-L_{g}\right)<1$.

$\left(H_{6}\right)$ Let $\varphi(t)>0$ and $\varphi^{p}(t)$ be a non decreasing function.

\section{Major Results}

In this section, we discuss the existence of solution of the nonlocal problem (2.2) and the UlamHyers-Rassias (U-H-R) stability.

Theorem 3.1. Assume that the hypotheses $\left(H_{1}\right)-\left(H_{6}\right)$ are satisfied. Then the nonlocal problem (2.2),

(i) has a unique continuous solution $z_{t} \in C$ and

(ii) has the U-H-R stability with respect to $\varphi \in C$.

Proof.

(i) By the Lyapunov's inequality ([18]), $\|\cdot\|_{2} \leq\|\cdot\|_{p}$. Therefore,

$\left\|y_{0}+\zeta\right\|_{2} \leq\left\|y_{0}+\zeta\right\|_{p}$ holds for all $p \geq 2$. Thus, equation (2.2) has a unique continuous solution $z_{t}$.

Next we prove that $z_{t} \in C$.

If $z_{t}$ is a continuous solution of (2.2), then

$$
z_{t}=z_{0}+g(y(.))+\int_{a}^{b} F\left(s, z_{s}\right) d s+\int_{a}^{b} G\left(s, z_{s}\right) d W_{s} .
$$

By assumption $\left(H_{3}\right)$ and the inequality $(a+b+c)^{p} \leq 3^{p-1}\left(a^{p}+b^{p}+c^{p}\right)$, we obtain

$$
\begin{aligned}
\left|z_{t}\right|^{p} & \leq 4^{p-1}\left\{\left|z_{0}\right|^{p}+|g(z)|^{p}\right. \\
& +\left|\int_{a}^{b} F\left(s, z_{s}\right) d s\right|^{p} \\
& \left.+\left|\int_{a}^{b} G\left(s, z_{s}\right) d W_{s}\right|^{p}\right\} .
\end{aligned}
$$


Next, we treat the right- hand side of (3.1) term by term as follows.

$$
\begin{aligned}
E\left|z_{0}\right|^{p}+|g(z)|^{p} \leq E\left|z_{0}\right|^{p}+E|\xi|^{p} . \\
\left|\int_{a}^{b} F\left(s, z_{s}\right) d s\right|^{p} \leq\left(\int_{a}^{b} L\left(1+\left|z_{s}\right|\right) d s\right)^{p} \\
\leq L^{p} 2^{p-1}\left(\left(\int_{a}^{b} d s\right)^{p}+\left(\int_{a}^{b}\left|z_{s}\right| d s\right)^{p}\right) \\
\leq L^{p} 2^{p-1}\left((b-a)^{p}+\left(\int_{a}^{b}\left|z_{s}\right| d s\right)^{p}\right) .
\end{aligned}
$$

Applying Holder's inequality to the last term on the right-hand side of (3.2) yields

$$
\begin{aligned}
\int_{a}^{b}\left|z_{s}\right| d s \leq & \left(\int_{a}^{b} d s\right)^{\frac{p-1}{p}}\left(\int_{a}^{b}\left|z_{s}\right|^{p} d s\right)^{1 / p} \\
& \leq(b-a)^{\frac{p-1}{p}}\left(\int_{a}^{b}\left|z_{s}\right|^{p} d s\right)^{1 / p},
\end{aligned}
$$

and

$$
\left|\int_{a}^{b} F\left(s, z_{s}\right) d s\right|^{p} \leq L^{p} 2^{p-1}(b-a)^{p-1}\left((b-a)+\int_{a}^{b}\left|z_{s}\right|^{p} d s\right) .
$$

Now applying (2.5) to the last term on the right-hand of (5.1) yields

$$
\begin{aligned}
E\left|\int_{a}^{b} G\left(s, z_{s}\right) d W_{s}\right|^{p} & \leq \gamma_{1} E \int_{a}^{b}\left|G\left(s, z_{s}\right)\right|^{p} d s \\
& \leq \gamma_{1} L^{p} E \int_{a}^{b}\left(1+\left|z_{s}\right|\right)^{p} d s \\
& \leq \gamma_{1} L^{p} E \int_{a}^{b} 2^{p-1}\left(1+\left|z_{s}\right|^{p}\right) d s \\
& \leq \gamma_{1} L^{p} 2^{p-1}\left((b-a)+\int_{a}^{b} E\left|z_{s}\right|^{p} d s\right) .
\end{aligned}
$$

Hence,

$$
E\left|z_{t}\right|^{p} \leq\left[\gamma_{2}+\gamma_{3} \int_{a}^{b} E\left|z_{s}\right|^{p} d s\right]
$$

where

$$
\gamma_{2}=4^{p-1}\left(E\left|z_{0}\right|^{p}+E|\xi|^{p}+L^{p} 2^{p-1}\left[(b-a)^{p}+\gamma_{1}(b-a)\right]\right)
$$

and

$$
\gamma_{3}=4^{p-1}\left(L^{p} 2^{p-1}\left[(b-a)^{p-1}+\gamma_{1}\right]\right) .
$$

Now by Lemma 2.1, we obtain

$$
E\left|z_{t}\right|^{p} \leq \gamma_{2} e^{\int_{a}^{b} \gamma_{3} d s} \leq \gamma_{2} e^{(b-a) \gamma_{3}}<\infty .
$$


Therefore, $z_{t} \in C$.

(ii) Assume $y_{t}$ is a solution of (2.4) and $z_{t}$ is a solution of (2.2). Then

$$
\begin{aligned}
\left|y_{t}-z_{t}\right|^{p} & \leq 4^{p-1}\left\{\mid y_{t}-\left[y_{0}+g(y)\right]\right. \\
& -\int_{a}^{b} F\left(s, y_{s}\right) d s-\left.\int_{a}^{b} G\left(s, y_{s}\right) d W_{s}\right|^{p} \\
& +|g(y)-g(z)|^{p} \\
& +\left|\int_{a}^{b}\left(F\left(s, y_{s}\right)-F\left(s, z_{s}\right)\right) d s\right|^{p} \\
& \left.+\left|\int_{a}^{b} G\left(s, y_{s}\right)-G\left(s, z_{s}\right) d W_{s}\right|^{p}\right\}(3.3) .
\end{aligned}
$$

Again, taking the expectation of each term of (3.3) we have

$$
E\left|y_{t}-\left[y_{0}+g(y)\right]+\int_{a}^{b} F\left(s, y_{s}\right) d s+\int_{a}^{b} G\left(s, y_{s}\right) d W_{s}\right|^{p} \leq \varphi^{p}(t) .
$$

By $\left(H_{5}\right)$ we obtain

$$
E|g(y)-g(z)|^{p} \leq L_{g}^{p} E|y-z|^{p},
$$

where $y_{0}=z_{0}$. By $\left(H_{2}\right),\left(H_{3}\right)$ and Holder's inequality, we obtain

$$
\begin{aligned}
\left|\int_{a}^{b}\left(F\left(s, y_{s}\right)-F\left(s, z_{s}\right)\right) d s\right|^{p} & \leq\left(\int_{a}^{b} K\left|y_{s}-z_{s}\right| d s \mid\right)^{p} \\
& \leq K^{p}\left(\int_{a}^{b} d s\right)^{p-1} \int_{a}^{b}\left|y_{s}-z_{s}\right|^{p} d s \\
& \leq K^{p}(b-a)^{p-1} \int_{a}^{b}\left|y_{s}-z_{s}\right|^{p} d s
\end{aligned}
$$

By applying (2.5), we obtain

$$
\begin{aligned}
E\left|\int_{a}^{b}\left(G\left(s, y_{s}\right)-G\left(s, z_{s}\right)\right) d W s\right|^{p} & \leq \gamma_{1} E \int_{a}^{b}\left|G\left(s, y_{s}\right)-G\left(s, z_{s}\right)\right|^{p} d s \\
& \leq \gamma_{1} K^{p} \int_{a}^{b} E\left|y_{s}-z_{s}\right|^{p} d s .
\end{aligned}
$$

Therefore,

$$
E\left|y_{t}-z_{t}\right|^{p} \leq\left[\gamma_{4} \varphi^{p}(t)+\gamma_{5} \int_{a}^{b} E\left|y_{s}-z_{s}\right|^{p} d s\right],
$$

where $\gamma_{4}=4^{p-1}, \gamma_{5}=4^{p-1} K^{p}\left((b-a)^{p-1}+\gamma_{1}\right)$ and $\left(1-L_{g}^{p}\right)<1$.

By Lemma 2.1, we get

$$
E\left|y_{t}-z_{t}\right|^{p} \leq \gamma_{4} \varphi^{p}(t) e^{\left(\int_{a}^{b} \gamma_{5}\right) d s} \leq \gamma_{4} \varphi^{p}(t) e^{\left(\gamma_{5}(b-a)\right)} .
$$

Thus,

$$
E\left|y_{t}-z_{t}\right|^{p} \leq M_{\varphi} \varphi(t)
$$

where $M_{\varphi}=\gamma_{4}^{\frac{1}{p}} e^{\left(\frac{\gamma_{5}(b-a)}{p}\right)}$. Hence, the nonlocal problem (2.1) has U-H-R stability and the proof is complete. 


\section{Examples}

To illustrate the established results, we consider the following nonlocal problems:

1. Given

$$
x_{t}=\frac{\eta}{12} x(\eta)+\int_{0}^{t} x_{s}^{3} d s+\int_{0}^{t} x_{s}^{2} d W s .
$$

$t \in[a, b] \equiv[0,1], 0<\eta<1$, and $p=2$.

Here $F(t, x)=x^{3}, G(t, x)=x^{2}$, and $g(x)=\frac{\eta}{12} x(\eta)$.

Next, we show that the hypotheses $\left(H_{1}\right)-\left(H_{6}\right)$ are satisfied.

$|F(t, x)-F(t, y)| \leq\left|x^{3}-y^{3}\right|$ and $|G(t, x)-G(t, y)| \leq\left|x^{2}-y^{2}\right|$ with $K=1$.

$|F(t, x)| \leq\left(1+\left|x^{3}\right|\right)$ and $|G(t, x)| \leq\left(1+\left|x^{2}\right|\right)$ with $L=1$.

$|g(x)-g(y)| \leq \frac{1}{12}|x-y|, \eta<1$ with $L_{g}=\frac{1}{12}$.

Also, the function $\varphi(t)>0$ satisfies the hypothesis $\left(H_{6}\right)$ and

$1-L_{g}=1-\frac{1}{12}<1$.

Therefore, the problem (4.1) is stable in the sense of U-H-R.

2. Given

$$
x_{t}=\frac{1}{4} x+\int_{0}^{t}\left(\frac{3}{2} x_{s}^{5}\right) d s-\int_{0}^{t} x_{s}^{3} d W s
$$

$F(t, x)=\frac{3}{2} x_{t}^{5}, G(t, x)=x^{3}$, and $g(x)=\frac{1}{4} x$. Here, the hypotheses $\left(H_{1}\right)-\left(H_{6}\right)$ will hold if

$$
\gamma_{5}=4^{p-1}\left(K_{F}^{p}(b-a)^{p-1}+K_{G}^{p} \gamma_{1}\right),
$$

where $K_{F}=\frac{3}{2}, K_{G}=1, L=1$, and $L_{g}=\frac{3}{2}$. Showing that the problem (4.2) has the U-H-R stability.

\section{Conclusion}

We have used the Gronwall lemma approach to study the existence and U-H-R stability of a continuous solution of a nonlocal stochastic Volterra integral equation. The established results are subject to the condition $\left(H_{5}\right)$, that is, $1-L_{g}<1$. The nonlinear examples have further justified the application of our model and have enriched the theory of stochastic Volterra equations.

\section{Acknowledgements}

The authors declare that there are no competing interests regarding the publication of this paper.

\section{Competing financial interests}

The authors will like to appreciate the anonymous reviewers for their valuable comments.

\section{References}

[1] Abdo, M.S., Saeed, A.M., Wahash, H.A. \& Panchal, S.K. On nonlocal problems for fractional integro-differential equation in Banach space. European J. of Scientific Research 151, 320-334 (2019).

[2] Ali, A., Shah, K. \& Baleanu, D. Ulam stability results to a class of nonlinear implicit boundary value problems of impulsive fractional differential equations. Advances in Difference Equations 2019, 5 (2019).

[3] András, S. \& Kolumbán, J.J. On the Ulam Hyers stability of first order differential systems with nonlocal initial conditions. Nonlinear Analysis: Theory, Methods Applications 82, 1-11 (2013). 
[4] Bishop, S. A., Ogundiran, M. O. \& Ogundile, O. P. On Stability of Quantum Stochastic Differential Equation. Int. Journal of Mech. Eng. Tech. 9, 367-374 (2018).

[5] Bishop, S. A., Anake, T. A. \& Agarana, M. C. On Continuous Dependence of Solution of Quantum Stochastic Differential Equation with Nonlocal Conditions. Proceedings of the WCECS, San Francisco, USA 1, 25-27 (2017).

[6] Byszewski, L. Continuous dependence of mild solutions, on initial nonlocal data. of the nonlocal semilinear evolution Cauchy problems, Czasopismo Techniczne 9 151-158 (2017).

[7] Castro, L. P. \& Simões, A. M. Hyers-Ulam-Rassias stability of nonlinear integral equations through the Bielecki metric. Mathematical Methods in the Applied Sciences 41, 17 (2018).

[8] Castro, L. P. \& Ramos, D. A. HyersUlamRassias Stability for a class of Nonlinear Volterra Integral Equations. Banach J. Math. Anal. 3, 36-43 (2009).

[9] Kucche, K. D. \& Shikhare, P. U. Ulam stabilities for nonlinear Volterra delay integrodifferential equations. Journal of Contemporary Mathematical Analysis 54, (2019).

[10] Kucche, K. D. \& Shikhare, P. U. Ulam stabilities for nonlinear VolterraFredholm delay integrodifferential equations. Int. J. Nonlinear Anal. Appl. 9, 145-159 (2018).

[11] Kucche, K. D. \& Shikhare, P. U. Ulam stabilities via Pachpattes inequality for Volterra Fredholm delay integrodifferential equations in Banach spaces. Note di Matematica 38, 67-82 (2018).

[12] Kucche, K. D. \& Shikhare, P. U. UlamHyers stability of integrodifferential equations in Banach spaces via Pachpattes Inequality. AsianEuropean Journal of Mathematics 11 1-19 (2017).

[13] Li, X., Wei, J. \& Xiang, J. Existence and HyersUlam stability results for nonlinear fractional systems with coupled nonlocal initial conditions. J. of Appl. Math. and Comput. 50 493-509 (2016).

[14] Ngo Phuoc Nguyen Ngoc Ulam-Hyers-Rassias Stability of a Nonlinear Stochastic Integral Equation of Volterra type. Differential Equations Applications 9 183-193 (2017).

[15] Nigar A., Bi, F., Shah, K. \& Khan, R. A. HyersUlam Stability of a Class of Nonlocal Boundary Value Problem Having Triple Solutions. Int. J. Appl. Comput. Math. 4, 29 (2018).

[16] Otrocol, D. \& Ilea, V. On the qualitative properties of functional integral equations with abstract Volterra operators. Results in Fixed Point Theory and Applications 13, 1-8 (2018).

[17] Pallavi U. S., Kishor D. K., \& Vanterlere da C. S. Analysis of Volterra Integrodifferential Equations with Nonlocal and Boundary Conditions via Picard Operator. Computational and Applied Mathematics 39208 (2020).

[18] Pinasco, J. P. Lyapunov-type Inequalities With Applications to Eigenvalue Problems. Springer New York Heidelberg Dordrecht London (2013).

[19] Raad, N. B. \& Ava SH. R. Existence and Uniqueness of Solution for Nonlinear Volterra Integral Equation. J. Duhok Univ. Pure and Eng. Sciences 14 25-29 (2011).

[20] Surez, A. \& Duarte, I. B. M. Nonlocal problems arising from the birthjump processes. Proceedings of the Royal Society of Edinburgh Section A: Mathematics 149 447-469 (2019).

[21] Viet Long, H. \& Phuong Thao, HT. Hyers-Ulam stability for nonlocal fractional partial integrodifferential equation with uncertainty. Journal of Intelligent and Fuzzy Systems 34, 233-244 (2018). 
[22] Vijayakumar, V., Murugesu, R., Poongodi, R. \& Dhanalakshmi, S. Controllability of SecondOrder Impulsive Nonlocal Cauchy Problem Via Measure of Noncompactness. Mediterranean Journal of Mathematics, February 14, 3 (2017).

[23] Zhenhai, L. \& Wang, R. A Note on Fractional Equations of Volterra Type with Nonlocal Boundary Condition. Abstract and Applied Analysis 8, 432941 (2013). 